\title{
Rapid sequence intubation: a survey of current practice in the South African pre- hospital setting
}

\author{
Johanna Catharina Botha ${ }^{1 *}$ (D) Andrit Lourens ${ }^{1,2}$ and Willem Stassen ${ }^{1}$
}

\begin{abstract}
Background: Rapid sequence intubation (RSI) is an advanced airway skill commonly performed in the pre-hospital setting globally. In South Africa, pre-hospital RSI was first approved for non-physician providers by the Health Professions Council of South Africa in 2009 and introduced as part of the scope of practice of degree qualified Emergency Care Practitioners (ECPs) only. The research study aimed to investigate and describe, based on the components of the minimum standards of pre-hospital RSI in South Africa, specific areas of interest related to current pre-hospital RSI practice.
\end{abstract}

Methods: An online descriptive cross-sectional survey was conducted amongst operational ECPs in the pre-hospital setting of South Africa, using convenience and snowball sampling strategies.

Results: A total of 87 participants agreed to partake. Eleven (12.6\%) incomplete survey responses were excluded while 76 (87.4\%) were included in the data analysis. The survey response rate could not be calculated. Most participants were operational in Gauteng $(n=27,35.5 \%)$ and the Western Cape $(n=25,32.9 \%)$. Overall participants reported that their education and training were perceived as being of good quality. The majority of participants $(n=69,90.8 \%)$ did not participate in an internship programme before commencing duties as an independent practitioner. Most RSI and post-intubation equipment were reported to be available; however, our results found that introducer stylets and/or bougies and end-tidal carbon dioxide devices are not available to some participants. Only 50 (65.8\%) participants reported the existence of a clinical governance system within their organisation.

Furthermore, our results indicate a lack of clinical feedback, deficiency of an RSI database, infrequent clinical review meetings and a shortage of formal consultation frameworks.

Conclusion: The practice of safe and effective pre-hospital RSI, performed by non-physician providers or ECPs, relies on comprehensive implementation and adherence to all the components of the minimum standards. Although there is largely an apparent alignment with the minimum standards, recurrent revision of practice needs to occur to ensure alignment with recommendations. Additionally, some areas may benefit from further research to improve current practice.

Keywords: Rapid sequence intubation (RSI), Pre-hospital, Minimum standards, Education and training, System requirements, Comprehensive clinical governance, South Africa

\footnotetext{
*Correspondence: jcbotha.vinkie@gmail.com

'Division of Emergency Medicine, Faculty of Health Sciences, University of Cape Town, Cape Town, South Africa

Full list of author information is available at the end of the article
}

\section{$\triangle B M C$}

(c) The Author(s). 2021 Open Access This article is licensed under a Creative Commons Attribution 4.0 International License, which permits use, sharing, adaptation, distribution and reproduction in any medium or format, as long as you give appropriate credit to the original author(s) and the source, provide a link to the Creative Commons licence, and indicate if changes were made. The images or other third party material in this article are included in the article's Creative Commons licence, unless indicated otherwise in a credit line to the material. If material is not included in the article's Creative Commons licence and your intended use is not permitted by statutory regulation or exceeds the permitted use, you will need to obtain permission directly from the copyright holder. To view a copy of this licence, visit http://creativecommons.org/licenses/by/4.0/ The Creative Commons Public Domain Dedication waiver (http://creativecommons.org/publicdomain/zero/1.0/) applies to the data made available in this article, unless otherwise stated in a credit line to the data. 


\section{Background}

Rapid sequence intubation (RSI) is an advanced airway skill commonly performed in the pre-hospital setting globally, by physician or non-physician providers $[1,2]$. RSI is regarded the gold standard for advanced airway management in critically ill and/or injured patients, mainly due to the optimal conditions created to facilitate endotracheal intubation (ETI) and by restricting the physiological effects of the procedure $[2,3]$. Arguably, the pre-hospital environment is not the ideal setting to perform high-risk procedures, such as RSI; however, some research suggests that certain patient groups, like those with severe traumatic brain injuries, may require immediate advanced airway interventions $[4,5]$.

Worldwide, experts raised concerns about the safety, efficacy, harm and delays that non-physician pre-hospital RSI may cause; nevertheless, the heterogeneity of available research makes comparisons and generalisability of conclusions regarding the value problematic [6, 7]. More recent studies, however, indicate higher endotracheal tube (ETT) first-pass and overall success rates amongst paramedics and/or student paramedics compared to earlier research [8-11]. Moreover, newer literature suggests that highly trained non-physician providers and increased experience may improve ETT pass success rates and reduce adverse events [12]. Lastly, the important role of a well-established clinical governance system, to deliver safe, quality patient care before, during and after ETI, ensuring optimal oxygenation, ventilation, normocapnia and normovolemia as well as preventing aspiration and other adverse effects associated with increased mortality and morbidity, should be underscored [13-15].

In South Africa (SA), pre-hospital RSI was first approved to be performed by degree qualified Emergency Care Practitioners (ECPs), non-physicians, by the Health Professions Council of South Africa (HPCSA) in 2009 [16]. With this addition to the scope of practice of ECPs, the HPCSA laid down the minimum standards forming the foundation and supportive framework to guide the implementation process and to ensure safe and effective practice [16]. Furthermore, a Position Statement published in 2010, endorsed by the Emergency Medicine Society of South Africa (EMSSA) and the Resuscitation Council of Southern Africa, provided additional details regarding RSI practice [1]. Since the approval, it is not known to what extent the minimum standards filtered down to the end-user level to support and enable ECPs to perform RSI safely and effectively.

Being a high-risk skill, RSI involves much more than merely passing the ETT [17]; therefore, to facilitate prehospital RSI, specific requirements such as training, system requirements and an appropriate clinical governance framework need to be considered before implementation and practice [1]. RSI, especially performed by non-physician providers, is a heavily debated topic globally $[5,7]$. As the concerns with regard to the safety and effectiveness are universal, a description of current pre-hospital non-physician RSI practice, albeit of an upper-middle-income country, may have a significant impact on the practice of the skill by non-physicians globally.

The research study aimed to investigate and describe, based on the components of the minimum standards of pre-hospital RSI in SA, specific areas of interest related to current pre-hospital RSI practice. The specific objectives were to describe pre-hospital training, system requirements and clinical governance systems in SA.

\section{Methods}

\section{Study design}

A descriptive cross-sectional survey was conducted amongst operational ECPs in the South African prehospital setting.

\section{Study setting and population}

SA is an upper-middle-income country, in Southern Africa, with a population of approximately 58 million in 2019 [18]. Pre-hospital emergency care (PEC) is provided by public, private or non-governmental organisations and includes platforms, such as ground ambulances, response vehicles, specialised ambulances and aeromedical.

Eligible study participants were operational ECPs, registered with the HPCSA, working in the South African pre-hospital setting. As mentioned, ECPs are the only group of emergency care providers allowed to perform pre-hospital RSI. With the implementation of the new emergency care clinical practice guidelines published in 2018, medication-facilitated intubation is no longer allowed [19]. For the study, the term "operational" entailed any PEC duties performed, in the capacity of an ECP, whether it is full-time or part-time with or without compensation.

Non-probability, convenience and snowball sampling strategies were used; however, due to the lack of reliable or published information on the exact number of operational ECPs in the South African pre-hospital setting, a sample size could not be calculated. Many HPCSAregistered ECPs are currently working abroad or employed in non-operational positions [20].

\section{Data collection}

We collected our data, using a trustworthy online survey tool, SurveyMonkey ${ }^{\circ}$. The survey (Additional file 1) was mindfully designed, using a variety of reputable 
resources [21-23]. To establish face validity, individuals knowledgeable on the study content and questionnaire design evaluated the survey and offered recommendations after which a pilot study was conducted amongst experienced, registered HPCSA ECPs working abroad. Recommendations were incorporated and the survey refined.

An electronic invitation and infographic, containing information and access to the online survey, were distributed to potential participants and key role players across SA, who in turn further distributed the survey invitation to other potential participants. Data were collected between 18 July and 18 September 2019. Electronic reminders were used to enhance study participation.

\section{Data analysis}

Data were analysed using IBM SPSS Statistics for Windows, version 25 [24]. Shapiro-Wilk tests were conducted to assess for normality. Demographic information (frequency, percentage, median $(\mathrm{M})$, interquartile range (IQR) and range) and survey responses (frequency and percentage) were expressed using descriptive statistics and presented with tables and graphs. The Pearson's chi-square test of independence was used to determine relationships between categorical variables and the Phi correlation coefficient to determine the strength of association. A $p$-value of $<0.05$ was considered statistically significant.

\section{Results}

\section{Demographics}

Eighty-seven participants agreed to partake and 11 $(12.6 \%)$ incomplete responses were excluded while the remainder $(n=76,87.4 \%)$ were included in the data analysis. Though the survey completion rate was $87 \%$, due to the sampling technique, the response rate could not be calculated as the exact sample population could not be determined (denominator unknown).

Most participants were operational in Gauteng $(n=27$, $35.5 \%)$ and the Western Cape $(n=25,32.9 \%)$ (Table 1). The overall years of emergency medical service (EMS) experience ranged between $<1$ and $27(\mathrm{M}=7, \mathrm{IQR}=5-$ 13) years while the years of experience as an ECP ranged between $<1$ and $12(\mathrm{M}=3, \mathrm{IQR}=2-6)$ years.

\section{Training}

For the theoretical (43.4\%), simulated practical (40.8\%), pharmacology (35.5\%), mechanical ventilation (46.1\%) and special circumstances (36.8\%) components, most participants reported the quality of education and training received to be good (Fig. 1). The quality of the clinical practice component was scored either average or excellent $(28.9 \%$ each) by most while $25 \%$ reported the
Table 1 Participant characteristics

\begin{tabular}{ll}
\hline Characteristics & $\boldsymbol{n}$ (\%) \\
\hline Province & \\
Gauteng & $27(35.5 \%)$ \\
Western Cape & $25(32.9 \%)$ \\
KwaZulu-Natal & $13(17.1 \%)$ \\
Eastern Cape & $5(6.6 \%)$ \\
Free State & $2(2.6 \%)$ \\
Mpumalanga & $1(1.3 \%)$ \\
Northern Cape & $1(1.3 \%)$ \\
Limpopo & $1(1.3 \%)$ \\
North West & $1(1.3 \%)$
\end{tabular}

$76(100 \%)$

\section{Job title}

Operational paramedic $\left(\mathrm{ECP}^{a}\right)$

Lecturer/Instructor/Trainer in $\mathrm{EMC}^{b} / \mathrm{EM}^{c}$

$17(22.4 \%)$

Operational flight paramedic $\left(\mathrm{ECP}^{a}\right)$

$7(9.2 \%)$

Manager/Administrative/Researcher in $\mathrm{EMC}^{b} / \mathrm{EM}^{c}$

$4(5.3 \%)$

No response

Years of total experience in pre-hospital EMS ${ }^{d}$ systems

$$
\begin{aligned}
& \text { 0-10 years } \\
& 11-20 \text { years } \\
& 21-30 \text { years }
\end{aligned}
$$

\section{Years of experience as $E C P^{a}$}

$$
0-5 \text { years }
$$

$$
\text { 6-12 years }
$$

\section{Organisation}

Private

Public (Government)

University/Training Institution

${ }^{\mathrm{a} E m e r g e n c y ~ C a r e ~ P r a c t i t i o n e r ~(E C P), ~}{ }^{\mathrm{b}}$ Emergency Medical Care (EMC), ${ }^{c}$ Emergency Medicine (EM), dEmergency Medical Services (EMS)

quality to be good. The theoretical component was perceived to be of the highest quality $(94.7 \%$ selected average, good or excellent) followed by pharmacology and simulated practice, while special circumstances and clinical practice were reported to be of lower quality (Additional file 2: Table S1).

Most participants $(n=69,90.8 \%)$ did not partake in an internship programme (e.g. working with a qualified ECP for a period after qualification) before commencing independent duties (Table 2). Almost $60 \%$ of participants $(n=45,59.2 \%)$ have not participated in formal 


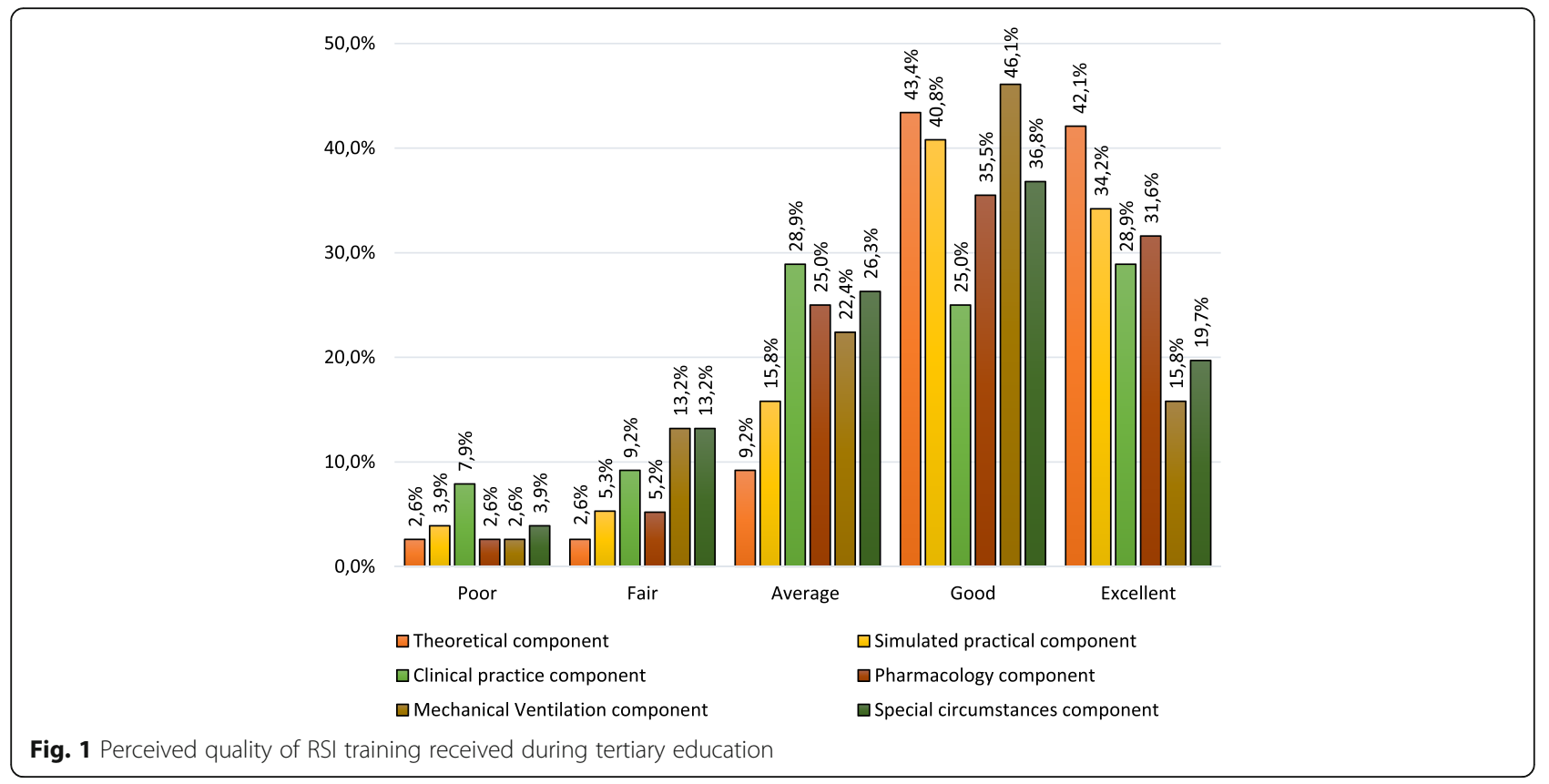

education and training activities specifically focusing on RSI, since graduation. No association was found between years' experience as an ECP ( $\leq 5$ years or $6-12$ years) and participation in an internship programme $(p=0.877)$ as well as between years' experience as an ECP $(\leq 5$ years or 6-12 years) and participation in formal RSI activities since graduation $(p=0.132)$.

\section{System requirements}

The availability of equipment to perform RSI and post-intubation management is indicated in Fig. 2. All participants $(n=76,100 \%)$ reported having an alternative airway device available, although the type of device varied. Sixty-eight (89\%) participants have either a bougie or a stylet available, $63(82.9 \%)$ reported the availability of both and three $(4 \%)$ neither device. End-tidal carbon dioxide $\left(\mathrm{EtCO}_{2}\right)$ measurement and monitoring capability were reported as 31 (40.8\%) having a capnometer and $67(88.1 \%)$ a capnograph whereas five participants reported not having any $\mathrm{EtCO}_{2}$ device available.

Table 2 Participation in an internship programme after qualification as an ECP

\begin{tabular}{ll}
\hline Internship period & $\boldsymbol{n}(\%)$ \\
\hline No participation & $69(90.8 \%)$ \\
$<1$ month & $4(5.3 \%)$ \\
$1-3$ months & $2(2.6 \%)$ \\
$>3$ months & $1(1.3 \%)$ \\
& $\mathbf{7 6 ( 1 0 0 \% )}$ \\
\hline
\end{tabular}

Forty-one $(53.9 \%)$ participants reported no equipment sharing amongst ECPs, while 32 (42.1\%) reported some sharing (missing data for 3 participants) (Additional file 2, Tables S2 and S3). Forty $(52.6 \%)$ participants reported the availability of an ETT cuff pressure manometer and 8 (10.5\%) indicated the availability of a video laryngoscope (VL) while $4(50 \%)$ reported that a VL was shared or is kept at the base. Table 3 depicts VL and ETT cuff manometer availability by EMS organisations. Ketamine, midazolam and morphine (99\% each) were more regularly available compared to etomidate $(92 \%)$ and fentanyl (8\%). Similarly, rocuronium (97\%) and suxamethonium (92\%) were more available, compared to vecuronium (9\%).

Thirty-four (44.7\%) participants specified that they have at least one dedicated assistant available during an RSI attempt, $29(38.2 \%)$ at least 2 and $10(13.2 \%)$ at least 3 while $3(3.9 \%)$ have no assistants available. The qualification held by the available RSI assistants is summarised in Additional file 2, Table S4. Most ( $n=34,44.74 \%)$ participants reported the perceived level of knowledge and skills of non-ECP emergency care providers to assist them during attempted RSI as average (Fig. 3). A few participants $(n=5)$ named the availability of three airway management short courses (namely Evidence-Based Management of Oxygenation, Ventilation and Airway (EMOVA), Airway Interventions \& Management in Emergencies and Advanced Airway \& Ventilation) in SA. Most participants reported that non-ECPs acquired the necessary knowledge and skills to assist during RSI, by working with 


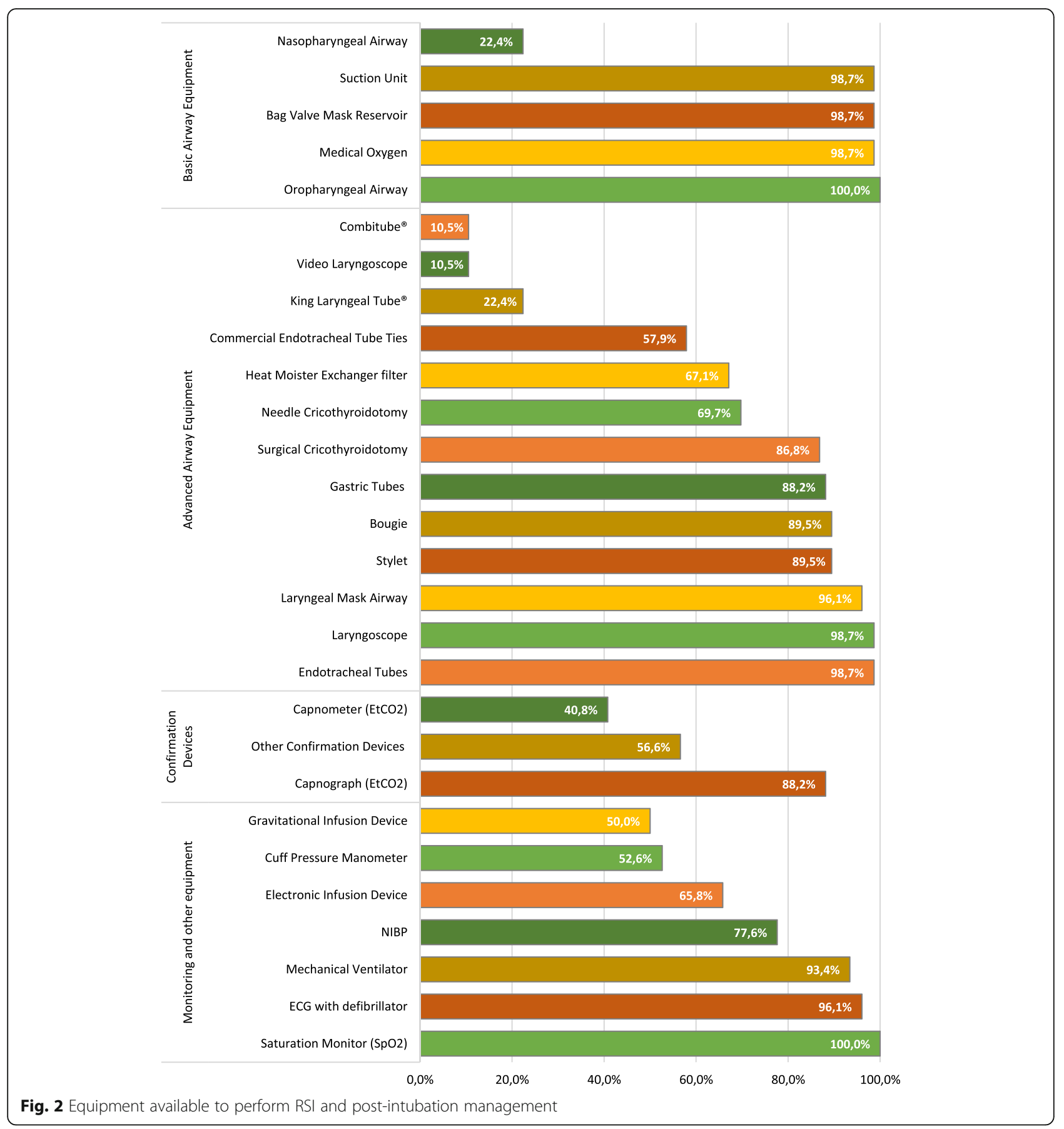

Table 3 Availability of video laryngoscope and ETT cuff manometer per EMS organisation type

\begin{tabular}{lll}
\hline Type of EMS organisation & $\begin{array}{l}\text { Video laryngoscope } \\
\boldsymbol{n}(\%)\end{array}$ & $\begin{array}{l}\text { ETT cuff manometer } \\
\boldsymbol{n}(\%)\end{array}$ \\
\hline Public (Government) & $2(2.6 \%)$ & $5(6.6 \%)$ \\
Private & $3(3.9 \%)$ & $27(35.6 \%)$ \\
Non-Governmental Organisations (NGOs) & $3(3.9 \%)$ & $4(5.3 \%)$ \\
University/Training Institution & $0(0 \%)$ & $4(5.3 \%)$ \\
& $\mathbf{8 ( 1 0 . 5 \% )}$ & $\mathbf{4 0 ( 5 2 . 6 \% )}$ \\
\hline
\end{tabular}


Question 22: "The knowledge and skills of non-ECP emergency care providers that assist me during every attempted RSI are

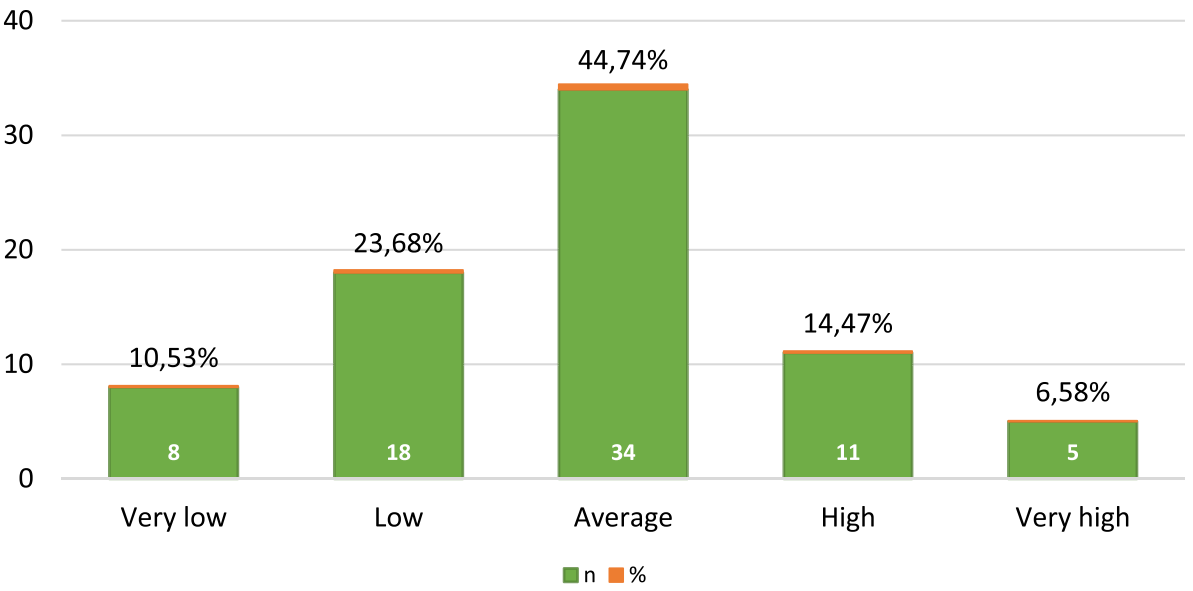

Fig. 3 ECP's perceived level of knowledge and skill of non-ECPs that assist during RSI

an ECP $(n=60,78.9 \%)$ and/or through informal training by an $\operatorname{ECP}(n=8,10.5 \%)$ (Additional file 2, Table S5).

\section{Comprehensive clinical governance system}

Fifty $(65.8 \%)$ participants reported a continuous quality improvement (CQI) or quality assurance (QA) department or representative within their organisation. Of these, 11 (22\%) never, 28 (56\%) sometimes and 11 (22\%) always receive feedback regarding attempted or performed RSI. Some participants describe the CQI in terms of RSI as "positive", "constructive", "discussions taking place", "problem identification" and "restorative". In some instances, peer reviews of clinical documentation are performed. Individuals that hold responsibilities for CQI are described as "Doctor", "EM Physician", "Senior ECP" and "person from outside the organisation". To a lesser degree, the CQI process was described as "investigative in nature" with "no continuous training and quality". In some cases, the person responsible for CQI holds a "lower qualification" compared to an ECP and thus "was not formally taught to perform RSI".

The submission of clinical documentation for an attempted/performed RSI is always required of 62 (81.6\%) participants, sometimes of $4(5.3 \%)$ and never of $10(13.2 \%)$. Most $(n=50,65.8 \%)$ participants indicated that clinical review and/or mortality and morbidity meetings to discuss attempted/performed RSI cases occur within the organisation; however, the frequency varied (Table 4). Thirty-one (40.8\%) participants reported that all RSI cases are captured on an organisational database, while the remaining was unsure $(n=24$, $31.6 \%)$ or reported no RSI database $(n=21,27.6 \%)$. A moderate association was found between organisations with a CQI/QA programme and organisations with an
RSI database $(p=0.006, \phi 0.316)$, suggesting those with a CQI/QA programme were more likely to have an RSI database.

Fifty-two (68.4\%) participants reported a formal consultation framework (e.g. senior ECP, peer and/or physician) within their organisation while 60 (78.9\%) occasionally consult informally with regard to performing RSI. A strong association was found between organisations with a formal consultation framework and those with a CQI/QA programme $(p<0.001, \phi 0.583)$ but not between the presence of a CQI/QA programme and practitioners who occasionally consult informally $(p=$ 0.134). Organisations with a formal consultation framework were more likely to also have a CQI/QA programme.

\section{Discussion}

To our knowledge, this study is the first to investigate and describe, based on the components of the minimum standards, specific areas related to South African prehospital RSI practice; therefore, the findings will be

Table 4 Clinical review and/or mortality and morbidity meetings

\begin{tabular}{ll}
\hline Number of meetings & $\boldsymbol{n}(\%)$ \\
\hline Never (zero per year) & $26(34.2 \%)$ \\
Rarely (once a year) & $19(25.0 \%)$ \\
Sometimes (every 6 months) & $11(14.5 \%)$ \\
Usually (every 3 months) & $7(9.2 \%)$ \\
Always (every month) & $12(15.8 \%)$ \\
Missing data & $1(1.3 \%)$ \\
& $\mathbf{7 6 ( 1 0 0 \% )}$ \\
\hline
\end{tabular}


valuable to understand current practice and make recommendations for improvement and further research.

\section{Demographics}

Considering the relatively recent addition of RSI to the scope of practice for ECPs [16] and the phased introduction of degree programmes and professionalisation of PEC education and training in SA since the early 2000 s $[25,26]$, a less clinically experienced ECP workforce, as we found, may be expected. Moreover, career progression and the international market may further compound the limited clinical experience of the workforce [20]. In the context of safe and effective pre-hospital RSI, this may be a concern, as the literature suggests an association between increased advanced airway management and RSI experience and higher ETI success rates and less adverse events contributing to lower mortality and morbidity [27-29]. The provincial representation of participants coincides with the highest populated provinces accumulatively, with the top three ranking provinces accounting for roughly half the country's population [30], and corresponds with the known distribution of operational ECPs and location of tertiary education institutions delivering ECP level education $[25,26]$.

\section{Training}

\section{Tertiary education}

Though the overall perceived quality of RSI tertiary education and training components, especially the theoretical component, were found to be commendable, the clinical practice and special circumstances components were suggested to be of lower quality. Various factors could be contributory including the method of delivery and/or inadequate learning opportunities during clinical practice placements. Recent literature suggests that the current education and training methods in SA do not seem to meet clinical practice learning objectives, which may lead to the potential inadequate preparation of paramedics for post-qualification independent practice [31]. These components may require enhancement through extensive collaboration between the relevant stakeholders to improve students' learning experiences [27, 31].

A limited number of opportunities to perform supervised RSI as a student ECP may be an additional factor potentially impacting the safety and quality of RSI by newly qualified practitioners as complication rates improve only after about 30 procedures [28]. Pre-hospital RSI experts advise that irrespective of being a physician or non-physician, ETI proficiency or competency requires considerably higher numbers to achieve at least a 90\% success rate [32, 33]. ECP students require 35 (11 pre-hospital) supervised ETIs and/or RSIs during their studies, 24 performed in an operating room under the supervision of an anaesthesiologist [11], which are contextually very different from pre-hospital RSI. This low frequency of supervised pre-hospital ETI/RSI may contribute to the component's perceived lower quality while additional factors may include the lack in the variety of clinical cases and patient types, or only observing ETI/RSI during clinical practice placements [34].

\section{Internship programme}

Although no known legislation requiring newly qualified ECPs to participate in an internship programme exists, some South African EMS organisations have such programmes in place, the features of which are unknown. As part of continuous learning to prevent skill decay and promote safe and effective skill delivery, the literature recommends supervised practice for non-physicians and physicians, especially in terms of advanced airway management or RSI [12, 13, 28, 35]. Recent evidence suggests that, although newly qualified paramedics were found to be competent, there was a reported lack of organisational and health systems knowledge, leadership, clinical judgement and decision-making skills [36]. We support the development and implementation of a structured internship programme for newly qualified ECPs in SA aimed at nourishing practitioner growth to deliver safe and effective RSI, as recommended by Moodley [31].

\section{Continuing professional development for ECPs}

In SA, ECPs are responsible to maintain and update their knowledge and skills post-qualification [16]. The HPCSA has a Continuing Professional Development (CPD) programme requiring practitioners to accumulate Continuing Education Units (CEUs); however, the contents are not specified [37]. In the context of fastdeveloping airway management approaches, research sources indicate that Continuing Medical Education (CME), which include theoretical, simulated and clinical practice activities, are crucial to prevent skill decay and perform RSI safely and effectively [13]. As mentioned by the participants, short courses tailored to provide continuous advanced airway management and RSI education and training in SA exist; however, ECPs are not necessarily required to attend these or similar courses. Attendance may be influenced by practitioner preference, course availability, affordability and/or specific employee currency certification requirements. We, therefore, recommend that RSI and/or advanced airway management-specific CME activities become mandatory and form part of the accumulation of CEUs towards the existing CPD programme to ensure ECPs are up to date with current best practice. 


\section{System requirements}

\section{Equipment and medication availability}

We found most mandatory airway management equipment and medications to be available to ECPs, with minimal reporting of equipment sharing.

Although a small percentage of participants reported not having either a stylet or a bougie available, it should be regarded as a concern, as this is one of the fundamental airway equipment when performing ETI/RSI, recommended by local and international guidelines [13, 38]. Not using these adjuncts may affect first-pass and overall success rates and possibly increase the risk of adverse events [2]. $\mathrm{EtCO}_{2}$ capnography is an important and mandatory tool for the confirmation of ETT placement and a valuable diagnostic tool that could promote safe and quality patient care and optimal mechanical ventilation [39]; thus, a lower than expected availability was of concern. The low availability of VL could be contributed to the recent introduction of the device in the pre-hospital setting and could also be considered as an expensive modality; subsequently, other expenditures and equipment purchase priorities may limit procurement. However, EMS organisations in low-resource settings may consider VL, as it may improve RSI success rates, decrease associated adverse events and facilitate faster ETI especially in trauma patients and patients with a difficult airway $[4,40,41]$ and should be supported by organisations and policymakers.

Correct inflation pressure with continuous cuff pressure monitoring has become important. Using the estimated predetermined volume of air to inflate the ETT cuff has been reported to be imprecise [42], while a recent SA study found ETT cuff pressure to be incorrect in $77 \%$ of patients on EC admission [43]. Although the complications of over- and under-inflation of ETT cuffs may not be noted in the emergency environment, both hold significant risks. To establish good practice, the use of an ETT cuff pressure manometer is recommended. The cost of commercial ETT cuff pressure manometers may contribute to the low availability; however, there is an alternative low-cost method to determine cuff pressure [44] which should be considered where commercial devices are unavailable.

\section{Assistants to perform RSI}

Consistent with EMSSA guidelines recommending at least one RSI assistant, our findings suggest that most ECPs have at least one; however, two is preferable [45]. Most international literature indicates and refers to a "team" that conducts pre-hospital RSI, highlighting the need for more than one competent assistant. More recent literature suggests that at least three knowledgeable and proficient team members should perform and assist during RSI [46].
Although airway management short courses are available, they primarily focus on educating and training those performing RSI. Nonetheless, these courses may provide some insight for non-ECP providers. To our knowledge, no short course specifically designed to equip non-ECPs with the necessary knowledge and skills to assist ECPs with RSI is currently offered in SA. A short course with the intent to train non-ECPs as RSI assistants may be extremely beneficial.

\section{Comprehensive clinical governance system}

The implementation and practice of safe and effective pre-hospital RSI cannot be guaranteed without clinical governance and quality improvement systems [1, 1315]. A good clinical governance system relies on a dynamic programme that supports and emphasises quality care, consultation, case feedback and clinical case reviews as part of independent practice and continuous learning [13, 14, 47]. The necessity of ongoing quality assurance, quality control and performance review was stipulated [1, 16]. Recording all RSI, whether attempted or performed, on a database is recommended [48], as it is an important component of clinical governance that can be used to facilitate improvement. In both hospital and pre-hospital settings, the implementation of a robust advanced airway programme, including the application of airway management algorithms, training, data collection and clinical reviews, has shown to significantly increase the first-pass success rate and RSI safety $[49,50]$.

\section{Study limitations}

To maximise validity, the questionnaire was mindfully designed, using reputable resources, expert input, and a pilot study was conducted. However, survey responses may have been influenced by a variety of factors such as personal beliefs and perceptions leading to the potential for bias, including social desirability bias as pre-hospital RSI performed by paramedics is a controversial topic globally.

The nature of the data collection tool may have influenced the results as break-offs, participant fatigue and misinterpretation of questions are likely. Non-response bias may have been introduced if the respondents that participated were systematically different from those that did not or if some eligible participants were not reached. Minor sections in the survey required participants to recall information regarding their perceived quality of training, from the not so recent past; therefore, various cognitive biases, including recall bias, could have been introduced, likely affected by work experiences or changes in their perception. Furthermore, the nonprobability sampling techniques could have produced a sampling bias that underrepresents certain demographic groups and individuals and restricted data analysis. In 
particular, the results were restricted by the limited representation of certain provinces; however, this may be representative of ECP distribution across the provinces in the country. Subsequently, the findings may not be generalisable to all EMS systems in SA.

Our study did not intend to provide a detailed description of current practice according to the components of the minimum standards but rather aimed to provide an overview of aspects that were deemed important for safe and effective pre-hospital RSI.

\section{Conclusion}

In this descriptive cross-sectional study, we found that there is plentiful alignment between the components of the minimum standards of pre-hospital RSI and current practice as perceived by ECPs; however, there are also some areas for improvement.

We found specific areas of university education and training that require more in-depth investigation and possible improvement initiatives. The implementation of an internship programme for newly qualified ECPs could complement pre-hospital clinical RSI encounters while the lack of availability and minimal participation of RSIspecific CME activities should be addressed. The importance of capable RSI assistants should be underscored; therefore, the need for the development and implementation of an RSI-specific education and training intervention for non-ECPs should be strongly considered.

A trustworthy and purposeful clinical governance system including various aspects for example monitoring, evaluating and managing risks, an RSI database, provision of education and training initiatives, etc. are needed in all EMS organisations that provide prehospital RSI in SA. The operational utility of existing quality assurance, control and improvement tools in some EMS organisations should be evaluated while frequent revision of practice is needed to ensure alignment with recommendations and current best practice.

\section{Abbreviations}

CEUs: Continuing Education Units; CME: Continuing Medical Education; CPD: Continuing Professional Development; CQI: Continuous Quality Improvement; ECP: Emergency Care Practitioner; EMS: Emergency Medical Services; EMSSA: Emergency Medicine Society of South Africa; EMOVA: Evidence-Based Management of Oxygenation, Ventilation and Airway; ETI: Endotracheal Intubation; ETT: Endotracheal Tube; HPCSA: Health Professions Council of South Africa; IQR: Interquartile Range; M: Median; NGO: Non-Governmental Organisation; PEC: Pre-hospital Emergency Care; QA: Quality Assurance; RSI: Rapid Sequence Intubation

\section{Supplementary Information}

The online version contains supplementary material available at https://doi. org/10.1186/s12245-021-00368-3.

Additional file 1:. Data collection tool

Additional file 2: Table S1 Perceived quality of education components $(n=76)$. Table S2 Equipment sharing amongst ECPs by Organisation ( $n=$
32). Table S3 Type of equipment shared amongst ECPs ( $n=32)$. Table S4 Qualifications of RSI assistants ( $n=76$ ). Table S5 Non-ECP education and training methods assist during RSI $(n=76)$

\section{Acknowledgements}

The authors would like to thank all participants and key role players within the industry that participated and/or distributed the electronic questionnaire invitation and infographic.

\section{Authors' contributions}

JB-conceptualisation of the study, study and survey design, data collection, analysis and interpretation and manuscript preparation. WS-study design and final manuscript review. AL_-study design, data analysis and interpretation and final manuscript review. All authors read and approved the final manuscript.

Funding

No funding was received for the research study.

Availability of data and materials

The datasets used and/or analysed during the current study are available from the corresponding author on reasonable request.

\section{Declarations}

Ethics approval and consent to participate

Ethical approval for this study was obtained from the Human Research Ethics Committee (HREC) of the Faculty of Health Sciences at the University of Cape Town (UCT) (HREC REF 204/2019).

Informed consent was obtained from each participant using a checkbox in the online survey.

\section{Competing interests}

The authors declare that they have no competing interests.

\section{Author details}

${ }^{1}$ Division of Emergency Medicine, Faculty of Health Sciences, University of Cape Town, Cape Town, South Africa. ${ }^{2}$ School of Nursing, Midwifery and Health, Faculty of Health and Life Sciences, Coventry University, Coventry, UK.

Received: 18 February 2021 Accepted: 27 July 2021

Published online: 17 August 2021

\section{References}

1. Stein C, Botha M, Kramer E, Nevin D, Dickerson R, Goldstein L, et al. Position statement. Pre-hospital rapid sequence intubation. S Afr Med J [Internet]. 2011;101(3):163 Available from: http://www.samj.org.za/index.php/samj/a rticle/view/4230.

2. Wallace C, McGuire B. Rapid sequence induction: its place in modern anaesthesia. Contin Educ Anaesthesia, Crit Care Pain [Internet]. 2014;14(3): 130-5. Available from: https://doi.org/10.1093/bjaceaccp/mkt047.

3. Okubo M, Gibo K, Hagiwara Y, Nakayama Y, Hasegawa K. The effectiveness of rapid sequence intubation (RSI) versus non-RSI in emergency department: an analysis of multicenter prospective observational study. Int J Emerg Med [Internet]. 2017;10(1):1-9. Available from: https://doi.org/10.11 86/s12245-017-0129-8.

4. Williamson K, Ramesh R, Grabinsky A. Advances in prehospital trauma care. Int J Crit IIIn Inj Sci [Internet]. 2011;1(1):44-50 Available from: https://www. ijciis.org/text.asp?2011/1/1/44/79281.

5. Haas B, Nathens AB. Pro/con debate: is the scoop and run approach the best approach to trauma services organization? Crit Care [Internet]. 2008; 12(5):224-35 Available from: http://ccforum.com/content/12/5/224.

6. Gunning M, Perkins Z, Crilly J, von Rahden R. Paramedic rapid sequence induction (RSI) in a South African emergency medical service: a retrospective observational study. South African Med J [Internet]. 2013; 103(9):632-7. Available from: http://www.scielo.org.za/pdf/samj/v103n9/21. pdf.

7. Lockey D, Porter K. Prehospital anaesthesia in the UK: position statement on behalf of the Faculty of Pre-hospital Care. Emerg Med J [Internet]. 2007; 
24(8):606-7. Available from: https://emj.bmj.com/content/emermed/24/6/43 7.full.pdf.

8. Brown III C, Cox K, Hurwitz S, Walls R. 4,871 emergency airway encounters by air medical providers: a report of the Air Transport Emergency Airway Management (NEAR VI: "A-TEAM") Project. West J Emerg Med [lnternet]. 2014;15(2):188-93. Available from: https://doi.org/10.5811/westjem.2013.11.1 8549

9. Stassen W, Lithgow A, Wylie C, Stein C. A descriptive analysis of endotracheal intubation in a South African Helicopter Emergency Medical Service. African J Emerg Med [Internet]. 2018;8(4):140-4. Available from: https://doi.org/10.1016/j.afjem.2018.07.002

10. Fouche PF, Stein C, Simpson P, Carlson JN, Doi SA. Nonphysician out-ofhospital rapid sequence intubation success and adverse events: a systematic review and meta-analysis. Ann Emerg Med [Internet]. 2017;70(4): 449-59. Available from: https://doi.org/10.1016/j.annemergmed.2017.03.026

11. Stein C. Student paramedic rapid sequence intubation in Johannesburg, South Africa: a case series. African J Emerg Med [Internet]. 2017;7(2):56-62. Available from: https://doi.org/10.1016/j.afjem.2017.01.005

12. McQueen C, Crombie N, Hulme J, Cormack S, Hussain N, Ludwig F, et al. Prehospital anaesthesia performed by physician/critical care paramedic teams in a major trauma network in the UK: a 12 month review of practice. Emerg Med J [Internet]. 2015;32(1):65-9. Available from: https://doi.org/1 0.1136/emermed-2013-202890

13. Crewdson K, Lockey D, Voelckel W, Temesvari P, Lossius HM. Best practice advice on pre-hospital emergency anaesthesia \& advanced airway management. Scand J Trauma Resusc Emerg Med [Internet]. 2019;27(1):1-7. Available from: https://doi.org/10.1186/s13049-018-0554-6

14. Lockey DJ, Crewdson K, Davies G, Jenkins B, Klein J, Laird C, et al. AAGBI: safer pre-hospital anaesthesia 2017: Association of Anaesthetists of Great Britain and Ireland. Anaesthesia [Internet]. 2017;72(3):379-90. Available from: https://doi.org/10.1111/anae.13779

15. Crewdson K, Rehn M, Lockey D. Airway management in pre-hospital critical care: a review of the evidence for a "top five" research priority. Scand J Trauma Resusc Emerg Med [Internet]. 2018;26(1):1-6. Available from: https:// doi.org/10.1186/s13049-018-0556-4

16. Health Professions Council of South Africa. Introduction of new scope of practice for registered Emergency Care Practitioners [Internet]. 2009. Available from: https://docplayer.net/7254330-Professional-board-foremergency-care.html.

17. Kovacs G, Law AJ. Airway management in emergencies. New York: McGrawHill Companies; 2008. p. 5-32.

18. Dadax. South Africa Population [Internet]. 2019. [cited 2019 Sep 13]. Available from: https://www.worldometers.info/world-population/south-a frica-population/

19. Health Professions Council of South Africa. Clinical Practice Guidelines [Internet]. 2018. Available from: https://www.hpcsa.co.za/Uploads/EMB/ CLINICAL\%20PRACTICE\%20GUIDELINES\%20\%20-\%20PROTOCOLS-\%2 0JULY\%202018.pdf.

20. Govender K, Grainger L, Naidoo R, MacDonald R. The pending loss of advanced life support paramedics in South Africa. African J Emerg Med [Internet]. 2012;2(2):59-66 Available from: https://www.sciencedirect.com/ science/article/pii/S2211419X11001595.

21. Lee C. The 10 step guide to questionnaire design [Internet]. RCU. 2015. [cited 2018 Oct 10]. Available from: http://www.rcu.co.uk/latest-news/the-1 0-step-guide-to-questionnaire-design/

22. Incorporated National Research Center. How to avoid survey fatigue [Internet]. 2016. [cited 2018 Oct 10]. Available from: https://blog.polco.us/ how-to-avoid-survey-fatigue.

23. Price PC, Jhangiani R, Chiang I-CA. Chapter 9: Survey research. In: Research Methods in Psychology. 2nd Canadian Edition. Victoria, B.C.: BCcampus; 2015. p. 180-98. Available from: https://opentextbc.ca/researchmethods/.

24. IBM. SPSS Statistics for Windows. Armonk, NY: IBM Corp; 2017.

25. Sobuwa S, Christopher LD. Emergency care education in South Africa: past, present and future. Australas J Paramed [Internet]. 2019;16:1-5. Available from: https://ajp.paramedics.org/index.php/ajp/article/view/647/814.

26. Department of Health: Republic of South Africa. National Emergency Care Education and Training Policy. 2017;1-16. Available from: https://www medbox.org/pdf/5e148832db60a2044c2d413c

27. Jacobs $P$, Grabinsky A. Advances in prehospital airway management. Int J Crit IIIn Inj Sci [Internet]. 2014;4(1):57-67. Available from: https://www.ijciis. org/text.asp?2014/4/1/57/128014.
28. Reed MJ. Intubation training in emergency medicine: a review of one trainee's first 100 procedures. Emerg Med J [Internet]. 2007;24(9):654-6. Available from: https://doi.org/10.1136/emj.2007.048678

29. Bossers SM, Schwarte LA, Loer SA, Twisk JWR, Boer C, Schober P. Experience in prehospital endotracheal intubation significantly influences mortality of patients with severe traumatic brain injury: a systematic review and metaanalysis. PLoS One [Internet]. 2015;10(10):1-26. Available from: https://doi. org/10.1371/journal.pone.0141034.

30. Statistics South Africa. Mid-year population estimates 2019 [Internet]. Statistics South Africa. Pretoria; 2019. Available from: https:/www.statssa. gov.za/publications/P0302/P03022019.pdf

31. Moodley K. An investigation into the clinical practicum experience of ALS paramedic students and their preparedness for professional practice [Internet]. Durban University of Technology; 2016. Available from: https:// openscholar.dut.ac.za/bitstream/10321/1551/1/MOODLEY_2016.pdf.

32. Toda J, Toda AA, Arakawa J. Learning curve for paramedic endotracheal intubation and complications. Int J Emerg Med [Internet]. 2013;6(1):1-8 Available from: http://www.intjem.com/content/6/1/38.

33. Gillett B, Saloum D, Aghera A, Marshall JP. Skill proficiency is predicted by intubation frequency of emergency medicine attending physicians. West $J$ Emerg Med [Internet]. 2019;20(4):601-9 Available from: http://escholarship. org/uc/uciem_westjem.

34. Michau R, Roberts S, Williams B, Boyle M. An investigation of theory-practice gap in undergraduate paramedic education. BMC Med Educ [Internet]. 2009;9(1):1-7 Available from: https://www.ncbi.nlm.nih.gov/pmc/articles/ PMC2694182/pdf/1472-6920-9-23.pdf.

35. Trimmel H, Beywinkler C, Hornung S, Kreutziger J, Voelckel WG. In-hospital airway management training for non-anesthesiologist EMS physicians: a descriptive quality control study. Scand J Trauma Resusc Emerg Med [Internet]. 2017;25(1):1-7. Available from: https://doi.org/10.1186/s13049-0170386-9

36. Reid D, Street K, Beatty S, Vencatachellum S, Mills B. Preparedness of graduate paramedics for practice: a comparison of Australian and United Kingdom education pathways. Australas J Paramed [Internet]. 2019;16:1-11. Available from: https://doi.org/10.33151/ajp.16.666

37. Health Professions Council of South Africa. Continuing Professional Development for the Health Practitioners [Internet]. 2017. Available from: https://www.hpcsa.co.za/Uploads/Professional_Practice/CPD/CPD Guidelines Sept 2017.pdf.

38. Wells M. Practice Guideline EM015 Rapid Sequence Intubation [Internet] Emergency Medicine Society of South Africa Guidelines. 2010. Available from: https://emssa.org.za/wp-content/uploads/2017/10/em017.pdf.

39. Owen R, Castle N. EtCO2: the key to effective prehospital ventilation. Emerg Med J [Internet]. 2006;23(7):578-9. Available from: https://doi.org/10.1136/ emi.2006.035907.

40. Boehringer B, Choate M, Hurwitz S, Tilney P, Judge T. Impact of video laryngoscopy on advanced airway management by critical care transport paramedics and nurses using the CMAC pocket monitor. Biomed Res Int [Internet]. 2015;1-6. Available from: https://doi.org/10.1155/2015/821302.

41. Gellerfors M, Larsson A, Svensén CH, Gryth D. Use of the Airtraq ${ }^{\circledR}$ device for airway management in the prehospital setting - a retrospective study. Scand J Trauma Resusc Emerg Med [Internet]. 2014;22(1):1-6 Available from: http://www.sjtrem.com/content/22/1/10.

42. Stewart S, Secrest J, Norwoord B, Zachary R. A comparison of endotracheal tube cuff pressures using estimation techniques and direct intracuff measurement. Am Assoc Nurse Anesth J [Internet]. 2003;71(6):443-7 Available from: https://pubmed.ncbi.nlm.nih.gov/15098531/.

43. Hardcastle TC, Faurie M, Muckart DJJ. Endotracheal tube cuff pressures and tube position in critically injured patients on arrival at a referral centre: avoidable harm? African J Emerg Med [Internet]. 2016;6(1):24-9. Available from: https://doi.org/10.1016/j.afjem.2015.09.002.

44. Botha JC. Ujuzi (Practical Pearl/Perle Pratique). African J Emerg Med [Internet]. 2016;6(4). Available from: https://doi.org/10.1016/j.afjem.2016.02. 002.

45. Wells M. Practice Guideline EM015B Rapid Sequence Intubation: Supporting Materials [Internet]. Emergency Medicine Society of South Africa Guidelines. 2010. Available from: http://emssa.org.za/wp-content/uploads/2017/10/ em017B.pdf.

46. Watkins J. The art of the airway: making critical decisions. Virginia EMS Symposium 2015 [Internet]. 2015. Available from: http://www.vdh.virginia. gov/content/uploads/sites/23/2016/05/AIR-202.pdf. 
47. Raitt J, Hudgell J, Knott H, Masud S. Key performance indicators for pre hospital emergency anaesthesia - a suggested approach for implementation [Internet]. Scandinavian Journal of Trauma, Resuscitation and Emergency Medicine. 2019;27:1-9. Available from: https://sitrem. biomedcentral.com/articles/10.1186/s13049-019-0610-x.

48. Pilbery R. How do paramedics learn and maintain the skill of tracheal intubation? A rapid evidence review. Br Paramed J [Internet]. 2018;3(2):7-21. Available from: https://doi.org/10.29045/14784726.2018.09.3.2.7.

49. Sakles JC, Augustinovich CC, Patanwala AE, Pacheco GS, Mosier JM. Improvement in the safety of rapid sequence intubation in the emergency department with the use of an airway continuous quality improvement program. West J Emerg Med [Internet]. 2019;20(4):610-8. Available from: https://doi.org/10.5811/westjem.2019.4.42343.

50. Olvera DJ, Stuhlmiller DFE, Wolfe A, Swearingen CF, Pennington T, Davis DP. A continuous quality improvement airway program results in sustained increases in intubation success. Prehospital Emerg Care [Internet]. 2018; 22(5):602-7. Available from: https://doi.org/10.1080/10903127.2018.1433734

\section{Publisher's Note}

Springer Nature remains neutral with regard to jurisdictional claims in published maps and institutional affiliations.

Ready to submit your research? Choose BMC and benefit from:

- fast, convenient online submission

- thorough peer review by experienced researchers in your field

- rapid publication on acceptance

- support for research data, including large and complex data types

- gold Open Access which fosters wider collaboration and increased citations

- maximum visibility for your research: over $100 \mathrm{M}$ website views per year

At $\mathrm{BMC}$, research is always in progress.

Learn more biomedcentral.com/submissions 